\title{
Fabrication of Superhydrophobic Surfaces on Aluminum Alloy Via Electrodeposition of Copper Followed by Electrochemical Modification
}

\author{
Ying Huang, D. K. Sarkar*, X-Grant Chen
}

(Received 8 July 2011; accepted 23 August 2011; published online 4 September 2011.)

\begin{abstract}
Superhydrophobic aluminum surfaces have been prepared by means of electrodeposition of copper on aluminum surfaces, followed by electrochemical modification using stearic acid organic molecules. Scanning electron microscopy (SEM) images show that the electrodeposited copper films follow "island growth mode" in the form of microdots and their number densities increase with the rise of the negative deposition potentials. At an electrodeposition potential of $-0.2 \mathrm{~V}$ the number density of the copper microdots are found to be $4.5 \times 10^{4}$ $\mathrm{cm}^{-2}$ that are increased to $2.9 \times 10^{5} \mathrm{~cm}^{-2}$ at a potential of $-0.8 \mathrm{~V}$. Systematically, the distances between the microdots are found to be reduced from $26.6 \mu \mathrm{m}$ to $11.03 \mu \mathrm{m}$ with the increase of negative electrochemical potential from $-0.2 \mathrm{~V}$ to $-0.8 \mathrm{~V}$. X-ray diffraction (XRD) analyses have confirmed the formation of copper stearate on the stearic acid modified copper films. The roughness of the stearic acid modified electrodeposited copper films is found to increase with the increase in the density of the copper microdots. A critical copper deposition potential of $-0.6 \mathrm{~V}$ in conjunction with the stearic acid modification provides a surface roughness of $6.2 \mu \mathrm{m}$ with a water contact angle of $157^{\circ}$, resulting in superhydrophobic properties on the aluminum substrates.
\end{abstract}

Keywords: Superhydrophobic aluminum surface; Water contact angle; Copper microdots; Surface roughness; Electrochemical modification

Citation: Ying Huang, D. K. Sarkar and X-Grant Chen, "Fabrication of Superhydrophobic Surfaces on Aluminum Alloy Via Electrodeposition of Copper Followed by Electrochemical Modification", Nano-Micro Lett. 3 (3), 160-165 (2011). http://dx.doi.org/10.3786/nml.v3i3.p160-165

\section{Introduction}

Wettability of a solid surface is one of the most important properties of materials, which depends on both the geometry and chemical composition of the surface [1]. Superhydrophobicity is a property that describes the non-wetting characteristics of materials surfaces. Inspired by nature, for example the inherent water repellent properties of lotus leaves surfaces, many researchers have been working on the preparation of such surfaces. The so-called lotus effect, which describes the rolling off of water drops on lotus leaves surfaces, is mainly due to the presence of two-tier micro- nanostructure patterns covered with low surface energy waxy materials on those surfaces [2-5]. The two-tier micro-nanostructures allow the air to be trapped in it, resulting in a heterogeneous composite surface, of air and the waxy tissue providing a very low surface energy, thereby enhancing the water contact angle of the lotus leaf surface rendering superhydrophobic properties [6]. The tremendous importance of superhydrophobic surfaces in areas such as antibiofouling paints for boats, biomedical applications, microfluidics, corrosion resistance, stain resistant textiles, inhibition of ice or snow adhesion, oxidation, air-drag reduction etc. [7-12]. Previously, we have reported several superhydrophobic

\footnotetext{
University Research Center on Aluminum (CURAL), University of Québec at Chicoutimi, Chicoutimi, QC, Canada, G7H 2B1

*Corresponding author. E-mail: dsarkar@uqac.ca
} 
surfaces fabricated with water roll-off properties using both chemical and plasma processes [13-17]. All these studies emphasized the importance of the coexistence of both surface roughness (micro-nanostructure) and the low surface energy coating in order for the surfaces to exhibit superhydrophobicity. These methods of fabrication utilized two-steps process involving micronanopatterning followed by the formation of a low surface energy surface via chemical or physical methods. Considering the importance of the coexistence of the micro-nanostructure and low surface energy in obtaining a superhydrophobic surface, we have demonstrated recently, it was possible to obtain such a surface even in a one-step process [18-21]. In one of the one-step methods, we have reported the engineering of superhydrophobic copper surfaces by electrochemical modification of copper electrode in an ethanolic stearic acid solution [18]. However, the similar procedure as we reported on copper surfaces [18], aluminum surfaces failed to show superhydrophobic properties. Therefore, in this study, the aluminum surfaces were initially electrodeposited with copper films and further electrochemically modified by ethanolic stearic acid solution to obtain superhydrophobic properties on aluminum surfaces. The morphological, structural and wetting characteristics of the composite films on these surfaces have been discussed.

\section{Experimental Details}

The cleaned aluminum substrates of AA6061 alloy were coated with copper films using an aqueous solution of $0.1 \mathrm{M} \mathrm{CuSO}_{4}$ and $0.1 \mathrm{M} \mathrm{NaClO}_{4}$ as used by Sarkar et al. [22] under potentials ranging from 0 to $-1 \mathrm{~V}$ for a deposition time of 10 minutes. The copper coated aluminum alloy substrates were electrochemically modified in ethanolic stearic acid solution for 30 minutes at $30 \mathrm{~V}$. The morphological and elemental analyses of the surfaces were performed using scanning electron microscope (SEM) and energy dispersive X-ray analysis (EDX). Ten SEM images of each copper coated sample prepared in a specific potential were analyzed using Clemex software (CLEMEX JS-2000, PE4.0) to determine the number density of the copper particles and their interparticle distances. The X-ray diffraction (XRD) analyses of the samples were carried out using a Bruker D8 Discover system. The wetting characteristics of the surfaces were examined using a First Ten Angstrom contact angle goniometer. The roughness of surfaces was measured using an optical profilometer (MicroXAM-100 HR 3D surface profilometer).

\section{Results and Discussion}

SEM images of copper films deposited on aluminum substrates are illustrated in Fig. 1 (a), (c), (e) and $(\mathrm{g})$, respectively. Furthermore, the SEM images of the stearic acid modified copper surfaces are shown in Fig. 1 (b), (d), (f) and (h). It is found that, the electrodeposited copper films are composed of microdots of copper which is identified by EDX (spectrum not shown) as well as by XRD analysis. By means of image analysis technique, the surface density of copper microdots (shown in Table 1 as well as in Fig. 2) is found to be $4.5 \times 10^{4} \mathrm{~cm}^{-2}$ and the average distance between the microdots (nearest neighboring particles) is $26.66 \mu \mathrm{m}$ for the film deposited at $-0.2 \mathrm{~V}$. Figure 2 also shows that an increase in the negative potential to $-0.4 \mathrm{~V}$ resulted in the increase of the number density to $8.3 \times 10^{4} \mathrm{~cm}^{-2}$ and the decrease of the distance between neighboring particles to $18.69 \mu \mathrm{m}$. However, the sharp increase of the number density of copper particles on aluminum substrate appeared at $-0.6 \mathrm{~V}$, where the number density and interparticle distance on copper film are $2 \times 10^{5}$ $\mathrm{cm}^{-2}$ and $13.15 \mu \mathrm{m}$, respectively. The particle density further increases with the increase of negative potential, and at $-0.8 \mathrm{~V}$ the number density of the particle is found to be $2.9 \times 10^{5} \mathrm{~cm}^{-2}$. Moreover, the sizes of the microdots are found to reduce with the increase in the negative deposition potentials. According to the Volmer-Weber growth mode, in case of electrochemical deposition process, the number of the nucleation cites increases with the increase of the negative deposition potential [23]. Therefore, it can be

Table 1 The number density and distance between the microdots of copper film deposited on aluminum substrates at different potentials. The roughness and the contact angle are also presented.

\begin{tabular}{|c|c|c|c|c|}
\hline $\begin{array}{l}\text { Applied DC } \\
\text { Voltage }(\mathrm{V})\end{array}$ & $\begin{array}{l}\text { Number density } \\
\text { of particles } \\
\text { (number } / \mathrm{cm}^{2} \text { ) }\end{array}$ & $\begin{array}{l}\text { Inter-particle } \\
\text { distance }(\mu \mathrm{m})\end{array}$ & $\begin{array}{l}\text { Roughness } \\
\qquad(\mu \mathrm{m})\end{array}$ & $\begin{array}{c}\text { Contact Angle } \\
\text { (degree) }\end{array}$ \\
\hline 0.0 & $1.1 \times 10^{4} \pm 2.5 \times 10^{3}$ & $51.31 \pm 22.67$ & $2.39 \pm 0.23$ & $115 \pm 1$ \\
\hline-0.2 & $4.5 \times 10^{4} \pm 4.9 \times 10^{3}$ & $26.66 \pm 9.71$ & $3.15 \pm 0.65$ & $130 \pm 5$ \\
\hline-0.4 & $8.3 \times 10^{4} \pm 4.6 \times 10^{3}$ & $18.69 \pm 6.62$ & $4.24 \pm 0.46$ & $143 \pm 4$ \\
\hline-0.6 & $2.0 \times 10^{5} \pm 7.1 \times 10^{3}$ & $13.15 \pm 4.00$ & $6.20 \pm 0.97$ & $157 \pm 1$ \\
\hline-0.8 & $2.9 \times 10^{5} \pm 2.8 \times 10^{4}$ & $11.03 \pm 3.33$ & $6.77 \pm 0.70$ & $157 \pm 1$ \\
\hline-1.0 & $2.4 \times 10^{5} \pm 2.5 \times 10^{4}$ & $8.66 \pm 2.59$ & $7.02 \pm 0.33$ & $157 \pm 1$ \\
\hline
\end{tabular}



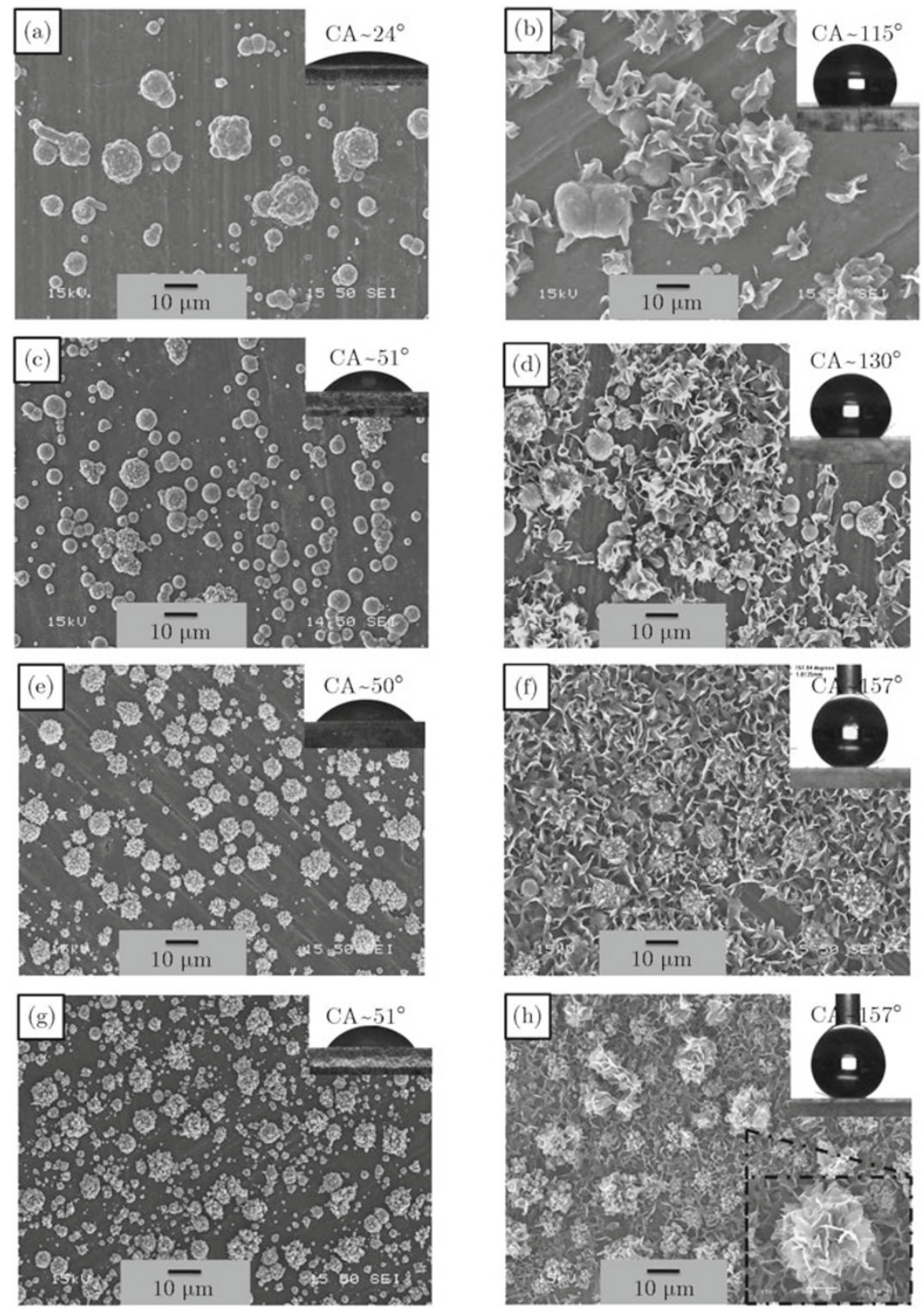

Fig. 1 SEM images (left column) of copper films deposited on aluminum substrates at (a) $-0.2 \mathrm{~V}$, (c) $-0.4 \mathrm{~V}$, (e) $-0.6 \mathrm{~V}$ and $(\mathrm{g})-0.8 \mathrm{~V}$ for 10 minutes. The SEM images (right column) of the same copper films after electrochemical modification in ethanolic stearic acid solution at $30 \mathrm{~V}$ for 30 minutes. The insets of Fig. 1 show the images of water drop on the respective surfaces.

concluded that the increase of the negative potential is responsible for the increase of the number density of the copper microdots and consequently, the decrease in the distances between them in the present study. The following equation can be used to express the density of the microdots as a function of the deposition potential as presented in Fig. 2 (a):

$$
\mathrm{N}=\exp (-3.45 \mathrm{~V}+9.99)
$$

where $\mathrm{N}$ is the number density of the microdots and $\mathrm{V}$ is the deposition potential. A plot of the logarithm of particle density vs. deposition potential evidently shows a linear relation [please see the extra documents].
Khelladi et al [24] also have observed a similar linear relationship between the deposition potential and the logarithm of the particles density while depositing copper on $\mathrm{n}-\mathrm{Si}(100)$ electrodes.

We have observed that the aluminum surfaces modified by ethanolic stearic acid solution under the influence of DC voltage did not show the superhydrophobic properties as we observed in the case of copper surfaces [18]. In order to obtain superhydrophobic properties on aluminum surfaces, the copper coated aluminum surfaces were further electrochemically modified in ethanolic stearic acid solution at $30 \mathrm{~V}$ for 30 minutes. The stearic acid modified copper microdots were decorated 

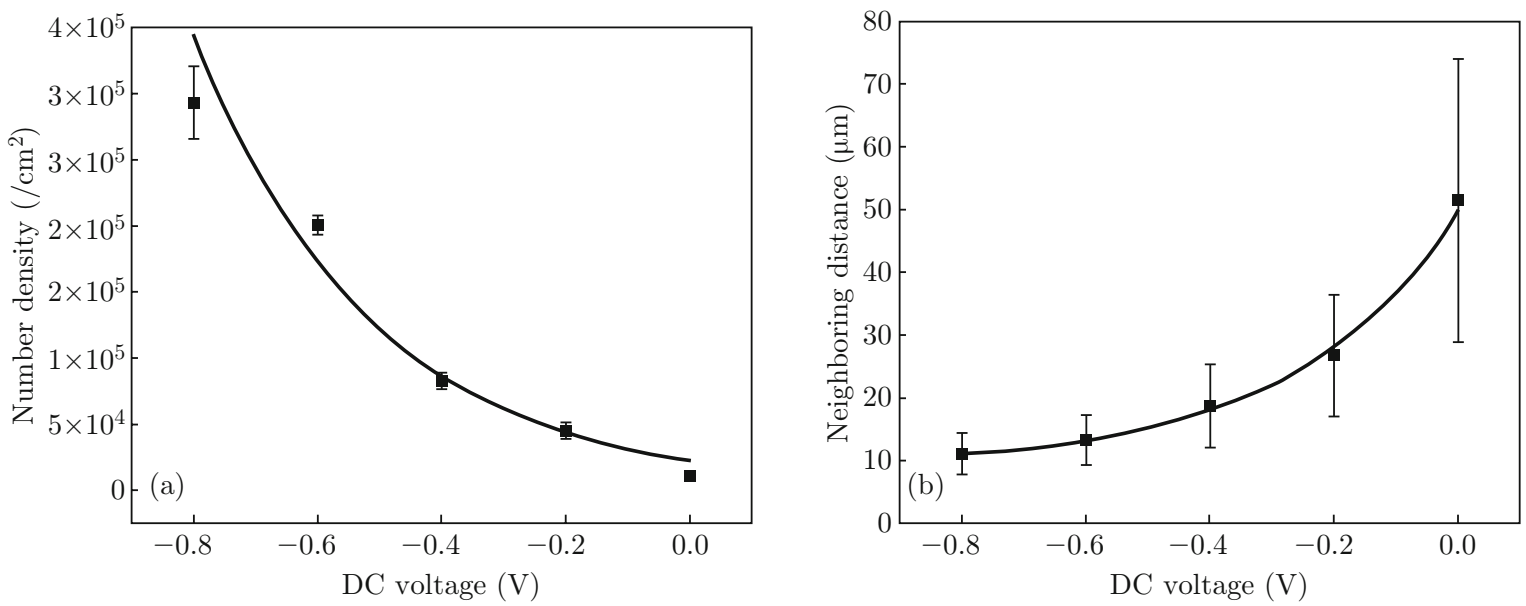

Fig. 2 (a) The number density of the copper microdots as a function of deposition potential, and (b) The distance between the copper microdots as a function of deposition potential.

with nanofibres resembling micro-nanostructured flower-like particles after stearic acid modification as shown in Fig. 1 ((b), (d), (f) and (h)). The flower-like morphologies formed on copper microdots coated aluminum substrates are very similar to those obtained from the electrochemically modified pure copper surfaces reported previously by us [18]. Further, it is interesting to note that the surface coverage on the stearic acid modified surfaces is higher covering nearly the whole area at higher negative potential as compared to a lower coverage at lower negative potential. The higher coverage might be due to the shorter interparticle distances between the copper micro-dots and the coalescence of the branches of copper stearate, a composition of copper and stearic acid, initiating from individual copper microdots in the empty space. The inset of Fig. 1 shows the image of water drops of the respective surfaces.

Figure 3(a) shows the XRD patterns of the copper films deposited on the aluminum substrates under the

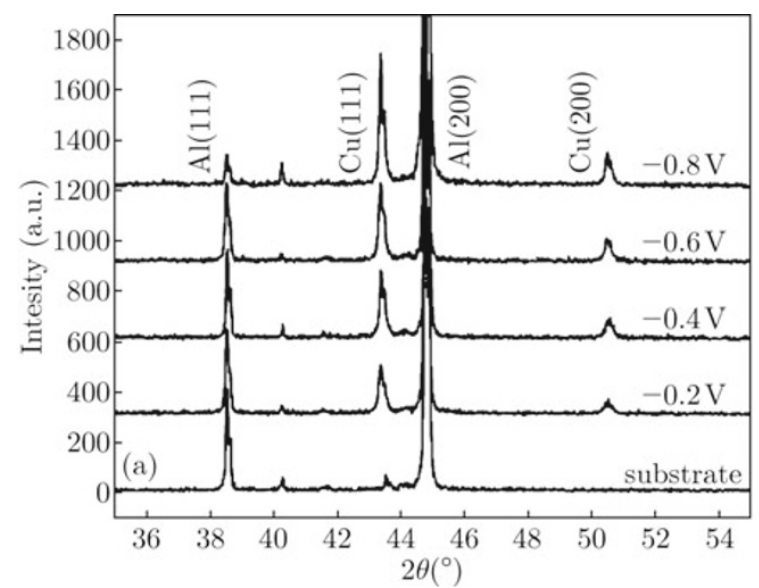

application of different deposition potentials of $-0.2 \mathrm{~V}$, $-0.4 \mathrm{~V},-0.6 \mathrm{~V}$ and $-0.8 \mathrm{~V}$ in the $2 \theta$ scan range of $35-$ $55^{\circ}$. The XRD patterns show two characteristic peaks at $38.47^{\circ}$ and $44.72^{\circ}$ of $\mathrm{Al}(111)$ and $\mathrm{Al}$ (200) planes, respectively arising from the aluminum substrate [25]. The XRD patterns also show the two characteristic peaks of the planes of $\mathrm{Cu}(111)$ and $\mathrm{Cu}(200)$ at $43.32^{\circ}$ and $50.45^{\circ}$, respectively [26] arising from copper films. The observation of two distinct planes of $\mathrm{Cu}(111)$ and $\mathrm{Cu}(200)$ confirm the copper deposition on aluminum substrates. The tiny peak at $43.32^{\circ}$ on aluminum substrate resulted from the small amount of copper in AA6061 aluminum alloy. Figure 3(a) also shows that the peak intensity of $\mathrm{Cu}(111)$ increases and that of $\mathrm{Al}$ (111) decreases with the increase of negative potential showing that the amount of copper deposition is higher at larger negative potential This observation is complementary with the SEM images (Fig. 1) which shows the deposition of large number of copper microdots with the increase of large negative potential.

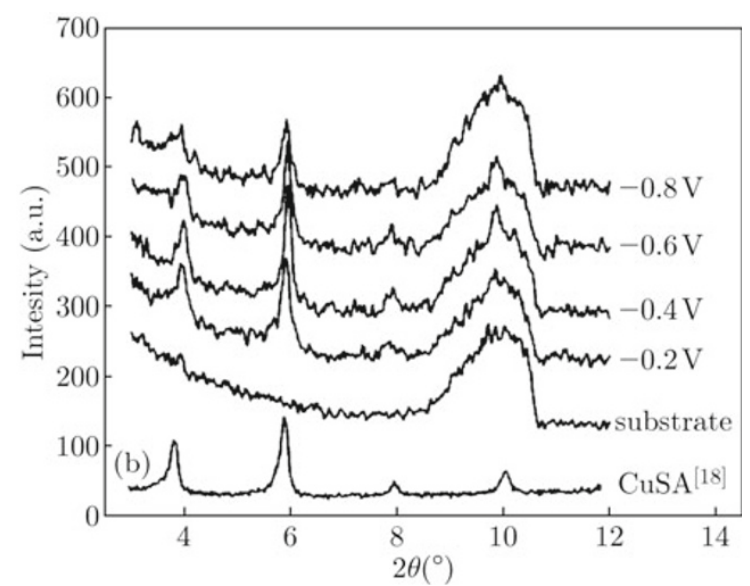

Fig. 3 (a) High angle XRD patterns of copper films deposited on aluminum substrates for the duration of 10 min under the application of various potentials followed by electrochemical modification in ethanolic stearic acid solution; (b) low angle XRD patterns of (a). CuSA is the XRD pattern of copper stearate films as reported by us in [18]. 
Figure $3(\mathrm{~b})$ shows the low angle $\left(2 \theta=3-11^{\circ}\right)$ XRD patterns of the electrochemically modified copper films composed of microdots of copper on aluminum substrates in ethanolic stearic acid solution. Figure 3(b) also displays the low angle XRD pattern of the aluminum substrate as well as that of copper stearate film (CuSA) prepared by electrochemically modified copper substrate in ethanolic stearic acid solution in our previous study [18]. The four distinct peaks present in Fig. 3(b) arises from the copper stearate $\left(\left(\mathrm{CH}_{3}\left(\mathrm{CH}_{2}\right)_{16} \mathrm{COO}\right)_{2} \mathrm{Cu}\right)$ formation from a reaction between stearic acid $\left(\mathrm{CH}_{3}\left(\mathrm{CH}_{2}\right)_{16} \mathrm{COOH}\right)$ and copper under the application of DC voltage. On the other hand, appearance of the broad peak at $9.45^{\circ}$ on the aluminum substrate might be due to the presence of some precipitate in the AA6061 aluminum alloy. Similarly, the XRD pattern of the four copper films deposited at $-0.2,-0.4,-0.6$ and $-0.8 \mathrm{~V}$ on aluminum substrates with further modification by stearic acid also show the four characteristics peaks of copper stearate. As the copper stearate consists of methylated $\left(\mathrm{CH}_{2}\right.$ and $\mathrm{CH}_{3}$ ) components, the electrochemical modification by stearic acid of the copper films reduces the surface energy of the copper coated aluminum surfaces.

Figure 4(a) and 4(b) depict the variation of surface roughness and water contact angle of electrodeposited copper film followed by electrochemical modification in ethanolic stearic acid solution. The surface roughness

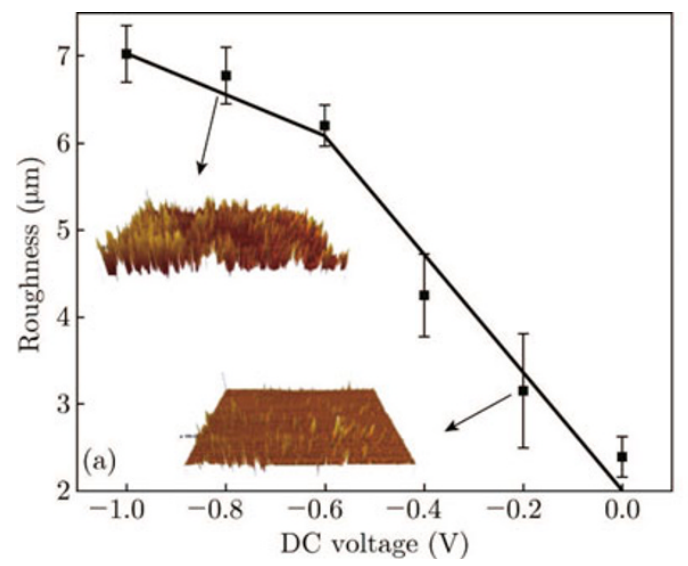

of electroless deposited copper films (applied potential equal to zero) after electrochemical modification with stearic acid is found to be $2.39 \mu \mathrm{m}$ and the water contact angle on the surface is found to be $115^{\circ}$. The surface roughness and the water contact angle are found to increase with increase in the negative deposition potential. The roughness and the water contact angle of the copper films increased to $3.15 \mu \mathrm{m}$ and $130^{\circ}$ respectively, for the copper films deposited at $-0.2 \mathrm{~V}$. Similarly, at $-0.4 \mathrm{~V}$, the roughness and water contact angle further increased to $4.24 \mu \mathrm{m}$ and $143^{\circ}$, respectively. At $-0.6 \mathrm{~V}$, the roughness further increased linearly with a slope of $-2.45 \mu \mathrm{m} / \mathrm{V}$ to $6.20 \mu \mathrm{m}$ and the water contact angle is found to be increased to $157^{\circ}$ demonstrating superhydrophobicity on these surfaces. It can be also observed in the Fig. 4(a) that the slope reduces to $-2.33 \mu \mathrm{m} / \mathrm{V}$ between -0.6 to $-1.0 \mathrm{~V}$. The obtained roughness at $-0.8 \mathrm{~V}$ is $6.77 \mu \mathrm{m}$ and the water contact angle on this surface is remain the same as $157^{\circ}$. The roughness increases slightly to $7.02 \mu \mathrm{m}$ on the surface of copper films deposited at $-1.0 \mathrm{~V}$, however, no further change in water contact angle was observed. It has been observed that the water contact angle increases with the increase of the surface roughness, however, a critical roughness of $6.2 \mu \mathrm{m}$ was essential in our study to obtain a surface with water contact angle of $157^{\circ}$ to exhibit superhydrophobicity. It is worthy to mention that we have obtained superhydrophobic surfaces having suitable roughness ranging between 6 to $7 \mu \mathrm{m}$.

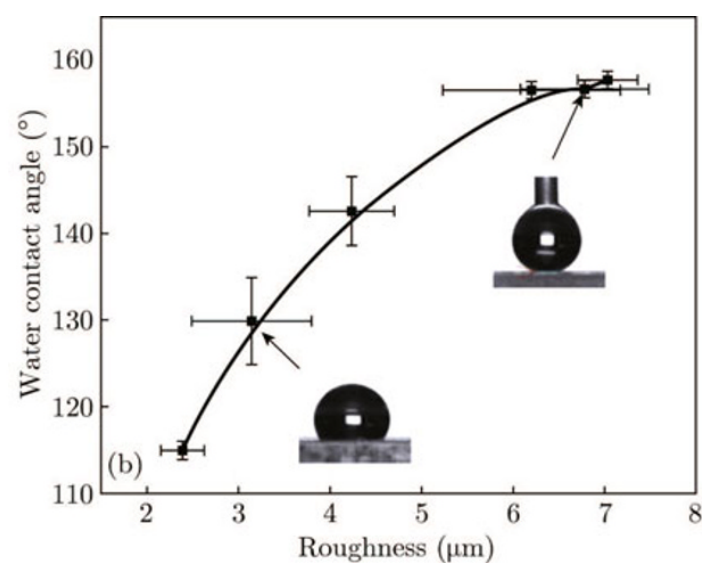

Fig. 4 (a) The variation of roughness vs. deposition potential; (b) variation of water contact angle vs. surface roughness on the stearic acid modified copper film deposited on aluminum surfaces. The inset of (a) shows the 3D images of the rough surfaces and (b) shows the images of water drops $(-0.2 \mathrm{~V}$ and $-0.8 \mathrm{~V})$.

Our observations on the increase of water contact angle with the increase of surface roughness are in good agreement with the observation of Rawal et al. [27], on hydrophobic zirconium oxynitride films where they have also reported that water contact angle increased with the increase of surface roughness. However, their observed surface roughness and water contact angles both are much smaller than our measured surface roughness and water contact angles.

\section{Conclusions}

Nanostructured superhydrophobic aluminum surfaces were prepared by two step processes: in the first 
step copper films were electrodeposited on aluminum surfaces and in the second step the copper films were electrochemically modified in ethanolic stearic acid solution. It has been observed that the copper films grow as microdots on aluminum surfaces. The surface densities of the microdots increase with the increase of the negative deposition potentials. On the other hand their sizes as well as the distances between the microdots reduce with the increase of the negative deposition potentials. The surface roughness and water contact angle of electrodeposited copper film followed by electrochemical modification in ethanolic stearic acid solution increase with the increase in negative copper deposition potentials. The stearic acid modified copper films deposited at $-0.6 \mathrm{~V}$ provides a surface roughness of $6.2 \mu \mathrm{m}$ with a water contact angle of $157^{\circ}$ providing superhydrophobic properties of aluminum surfaces.

\section{Acknowledgment}

We acknowledge the financial support provided by the Natural Sciences and Engineering Research Council of Canada (NSERC). We also thank Prof. Dyugu Kocaefe for providing access to contact angle measurements. We also thank N. Saleema of Aluminum Technology Centre, National Research Council of Canada (ATC-NRC) for the critical reading of the manuscript.

\section{References}

[1] T. L. Sun, L. Feng, X. F. Gao and L. Jiang, Accounts Chem. Res. 38, 644 (2005). http://dx.doi.org/10. 1021/ar040224c

[2] W. Barthlott and C. Neinhuis, Planta 202, 1 (1997). http://dx.doi.org/10.1007/s004250050096

[3] X. Gao and L. Jiang, Nature 432, 36 (2004). http:// dx.doi.org/10.1038/432036a

[4] Y. Zheng, X. Gao and L. Jiang, Soft Matter 3, 178 (2007). http://dx.doi.org/10.1039/b612667g

[5] J. Huang, X. Wang and Z. L. Wang, Nano Lett. 6, 2325 (2006). http://dx.doi.org/10.1021/nl061851t

[6] D. K. Sarkar and N. Saleema, Surf. Coat. Tech. 204, 2483 (2010). http://dx.doi.org/10.1016/j. surf coat. 2010.01.033

[7] A. Scardino, R. D. Nys, O. Ison, W. O'Connor and P. Steinberg, Biofouling 19, 221 (2003). http://dx.doi. org/10.1080/0892701021000057882

[8] A. Singh, L. Steely and H. R. Allcock, Polym. Prepr. (ACS, Div. Polym.Chem.) 46, 599 (2005).
[9] H. Gau, S. Herminghaus, P. Lenz and R. Lipowsky, Science 46, 283 (1996).

[10] T. Liu, Y. Yin, S. Chen, X. Chang and S. Cheng, Electrochimica Acta 52, 3709 (2007). http://dx.doi.org/ 10.1016/j.electacta. 2006.10.059

[11] K. Satoh and H. Nakazumi, J. Sol-Gel Sci. Tech. 27, 327 (2003). http://dx.doi.org/10.1023/A: 1024025104733

[12] D. K. Sarkar and M. Farzaneh, J. Adhes. Sci. Technol. 23, 1215 (2009). http://dx.doi.org/10.1163/ 156856109X433964

[13] D. K. Sarkar, M. Farzaneh and R. W. Paynter, Mater. Lett. 62, 1226 (2008). http://dx.doi.org/10.1016/ j.matlet.2007.08.051

[14] A. Safaee, D. K. Sarkar and M. Farzaneh, Appl. Surf. Sci. 254, 2493 (2008). http://dx.doi.org/10.1016/ j.apsusc. 2007.09.073

[15] D. K. Sarkar, M. Farzaneh and R. W. Paynter, Appl. Surf. Sci. 256, 3698 (2010). http://dx.doi.org/10. 1016/j . apsusc. 2009.12.049

[16] N. Saleema, D. K. Sarkar, Farzaneh M. In: Mittal KL, editor. Contact angle, wettability and adhesion, vol. 5 . Leiden: VSP/Brill; 2008. p. 279.

[17] D. K. Sarkar and M. Farzaneh In: Mittal KL, editor. Contact angle, wettability and adhesion, vol. 5. Leiden: VSP/Brill; 2008. p. 271.

[18] Y. Huang, D. K. Sarkar and X. Grant, Chen, Mater. Lett. 64, 2722 (2010). http://dx.doi.org/10.1016/ j.matlet.2010.09.010

[19] N. Saleema, D. K. Sarkar, R. W. Paynter and X. G. Chen, ACS Appl. Mater. Interface. (Letters) 2, 2500 (2010). http://dx.doi.org/10.1021/am100563u

[20] D. K. Sarkar and R. W. Paynter, J. Adhesion Sci. Technol. 24, 1181 (2010). http://dx.doi.org/10.1163/ $016942409 \times 12598231568546$

[21] D. K. Sarkar and N. Saleema, Surf. Coat. Technol. 204, 2483 (2010). http://dx.doi.org/10.1016/ j.surf coat. 2010.01.033

[22] D. K. Sarkar, X. J. Zhou, A. Tannous and K. T. Leung, J. Phys. Chem. B (Letters) 107, 2879 (2003). http:// dx.doi.org/10.1021/jp0269524

[23] M. Volmer and A. Z. Weber, Phys. Chem. 119, 277 (1926).

[24] M. R. Khelladi, L. Mentar, A. Azizi, A. Sahari and A. Kahoul, Mater. Chem. Phys. 115, 385 (2009). http:// dx.doi.org/10.1016/j.matchemphys. 2008.12.017

[25] JCPDS Al (01-085-1327).

[26] JCPDS Cu (01-085-1326).

[27] S. K. Rawal, A. K. Chawla, V. Chawla, R. Jayaganthan and R. Chandra, Mater. Sci. Eng. B 172, 259 (2010). http://dx.doi.org/10.1016/j. mseb. 2010.05 .027 